


\section{Misticismo y escritura en el Tractatus logico-philosophicus}

\section{Mysticism and writing in the Tractatus logico-philosophicus}

Laura Adriana Hernández Martínez Universidad Autónoma Metropolitana-Iztapalapa, México lauraxanum@hotmail.com

Resumen: En este ensayo se plantea que la escritura filosófica de Wittgenstein es una escritura mística, que es heredera de la filosofía mística alemana, iniciada por Böhme y posteriormente desarrollada por los místicos barrocos, entre quienes destaca Angelus Silesius, a quien Wittgenstein leyó en el frente austríaco, durante la Primera Guerra Mundial. Dicha influencia se aprecia de manera muy clara en la expresión aforística del Tractatus logico-philosophicus, que recupera la poética paradójica y sintética de los epigramas de Angelus Silesius en la exposición del análisis lógico del lenguaje, que distingue entre aquello que se puede decir y lo que solo se puede mostrar en el lenguaje.

Palabras clave: Wittgenstein, Silesius, mística, escritura filosófica, trascendencia.

Abstract: This essay considers Wittgenstein's philosophical writing as a mystic writing, heir to the German philosophical mysticism that begins with Jakob Böhme and further developed by the German baroque mystics, notably Angelus Silesius, who Wittgenstein read on the Austrian war front in the First World War. This influence is clear in the aphoristic expression of the Tractatus Logico-Philosophicus, with which Wittgens- 
tein recovers the synthetic and paradoxical poetics of Angelus Silesius epigrams, through the exposition of the linguistic logical analysis which distinguishes between what can be said, and what only can be shown in language.

Keywords: Wittgenstein, Silesius, Mystics, Philosophical Writing, Transcendence.

Recibido: 20 de enero de $202 \mathrm{I}$

Aceptado: Io de marzo de $202 \mathrm{I}$ https://dx.doi.org/IO.I 5 I 74/rv.vi 3i28.599

En memoria de Rubén Chuaqui Admirado y querido maestro

La filosofía como forma-de-vida y no como flatus vocis gira siempre alrededor de la locura (de Dios).

OsCAR DEL BARCo

\section{Ética y poética}

$\mathrm{Cl}^{1}$ Tractatus logico-philosophicus (1921) es el único libro que CWittgenstein publicó en vida, pero su escritura se desarrolló a lo largo de la Primera Guerra Mundial donde participó en tareas de enorme peligro como voluntario. Terminó de escribirlo en la casa de su tío Paul, cerca de Salzburgo, donde pasó el verano de 1918, después de que su tío lo encontrara por casualidad en la esta- 
ción de trenes decidido a suicidarse, al enterarse de la muerte de su entrañable amigo, David Pinsent, a quien está dedicado el libro. ${ }^{1}$

La filosofía contenida ahí es el fruto de su trabajo en lógica que inició con Russell en 1912 y que empezó a cobrar forma los meses que pasó en Skjolden entre 1913 y 1914, cuando Edward Moore fue a visitarlo a Noruega, y donde ya aparecía la distinción fundamental entre lo que es decible y lo que es mostrable en el lenguaje, que da sentido a su decisión de escribirlo en aforismos numerados, subrayando así la importancia de atender a esta distinción también en la expresión escrita y dotándolo, con ello, de ese carácter místico que le ha valido el estigma de ser un libro críptico. Y si bien este texto es crucial en la historia de la filosofía del siglo XX y goza de gran fama, tuvo una mala recepción cultural en su momento, debido precisamente a una extraña escritura que no combinaba con el impulso hacia una filosofía fundada en el pensamiento matemático, como era la filosofía analítica que Russell y Wittgenstein crearon en su primera versión, conocida como atomismo lógico.

Al recibir el manuscrito en 1919, Frege le comunicó que consideraba un error haberlo escrito en aforismos porque provocaba que los lectores ya no le dieran importancia a la exposición científica al ser subyugados por un lenguaje poético. ${ }^{2}$ Por su parte, Russell fue condescendiente y prefirió omitir ese "defecto", pues aceptó escribir la introducción que le fue requerida a Wittgenstein como aval para que la obra pudiera ser publicada, como muestra de que reconocía su aportación para el análisis lógico del lenguaje. Sin embargo, Wittgenstein la rechazó en una airada carta donde le reclama la falta de comprensión de su obra, algo que ya presentía cuando le escribe desde el campo de concentración de Montecasi-

${ }^{1}$ En esa primera versión, conocida como el Prototractatus, aparece al final una nota donde agradece a su tío Paul Wittgenstein y a Bertrand Russell por el apoyo que le dieron (Wittgenstein, 1971: 2).

${ }^{2}$ Para una interesante discusión sobre este tema, véase J. Bremer (2020). 
no en 1918, avisándole que le ha enviado el único manuscrito que existe del Tractatus, en una carta que termina con estas palabras: "Cálidos recuerdos, y no pienses que todo lo que tú no entiendes es mera estupidez" (Wittgenstein, 1979: 66).

Wittgenstein había intentado sin fortuna publicarlo antes en Viena, que le parecía el lugar más apropiado para presentar una obra sobre ética y lógica, por ser un tema central en la cultura vienesa a partir de Sexo y carácter, el libro de Otto Weininger. Decidió entonces pedirle a Von Ficker, editor del periódico Der Brenner, que se encargara de ello, en una famosa carta donde le explica que "la obra es estrictamente filosófica y al mismo tiempo literaria, pero en ella no hay parloteo inútil” (Monk, 1994: 176). La respuesta de Von Ficker no fue la esperada, pues le respondió que las obras "estrictamente científicas" no eran su campo y que sería difícil publicarla, pero le prometió intentarlo. Wittgenstein se muestra sorprendido ante ello y reitera que la finalidad del libro es ética y no científica, por lo que la parte más importante del libro es la parte que no ha escrito y no la que está escrita. Finalmente, lo conmina a leer el prólogo y la conclusión para tener una idea clara del tema que se trataba (176).

Ahora bien, el aforismo con que concluye el Tractatus, exhorta a guardar silencio ante lo indecible, lo cual no significa que no se deba producir lenguaje -como muchas veces se piensa- sino que no se debe pretender decir algo con sentido (lógico) sobre lo trascendente. Se trata de una posición ética que está enunciada como una tarea lingüística en el aforismo 6.54 (el penúltimo), donde Wittgenstein declara que su libro está escrito como una escalera de sinsentidos, ${ }^{3}$ que es el modus loquendi con que se muestra, en

${ }^{3}$ En el aforismo 6.54, Wittgenstein se refiere a su escritura así: "Mis proposiciones son esclarecedoras de este modo: que quien me comprende acaba por reconocer que carecen de sentido, siempre que el que las comprenda haya salido a través de ellas fuera de ellas. (Debe, pues, por así decirlo, tirar la escalera 
el lenguaje, el límite del sentido, en concordancia con lo que se señala en el aforismo 6.522: "Lo inexpresable, ciertamente existe. Se muestra, es lo místico".

Esta concepción mística del lenguaje -con la que Wittgenstein hace patente la enorme limitación de la ciencia sobre lo que puede decir del mundo, que es muy poco: apenas cuáles son los hechos que acaecen, pero nunca su sentido como totalidad- tiene ecos de los místicos del barroco alemán, principalmente de Angelus Silesius (1624-1677), cuyos bellísimos epigramas, reunidos en El peregrino querúbico, fueron leídos por Wittgenstein durante la guerra, como sabemos por la carta que Russell le envía a Lady Ottoline desde La Haya, después del encuentro que tuvo con Wittgenstein para hablar del Tractatus, en diciembre de 1919: "En su libro había percibido un cierto aroma de misticismo pero me quedé asombrado cuando descubrí que se había vuelto un místico completo. Lee a autores como Kierkegaard y Angelus Silesius, y considera seriamente la posibilidad de hacerse monje" (Wittgenstein, 1979: 75-76).

Andrew Weeks (1993) coincide en que el misticismo de Wittgenstein es el de esta tradición alemana que hereda mucho del pensamiento del filósofo zapatero, Jacob Böhme (1575-1624), cuyos textos también serán fuente de inspiración para los románticos alemanes y filósofos como Hegel (Seijas, 2010: 1, nota 2). El Tractatus compartiría con ese misticismo una teofanía que ve el mundo como un signo indescifrable, pues la tesis del aforismo $6.522 \mathrm{de}$ que el mundo como totalidad es indecible y sólo se muestra en el lenguaje, es una imagen que Weeks (236-237) encuentra muy

después de haber subido.) / Debe superar estas proposiciones; entonces tiene la justa visión del mundo" (énfasis mío). 
próxima a la concepción del mundo de Böhme como Mysterium magnum. ${ }^{4}$

También Isidoro Reguera considera en sus comentarios a los Diarios secretos que, para entender lo que ahí escribió Wittgenstein, hay que reconocer la influencia de Angelus Silesius y su mística böhmeana, "que va más allá de la razón, pero también de la ignorancia y el silencio negativos, permitiéndole un discurso de lo inefable" (Wittgenstein, 1991: 202).

Resulta de gran interés que Alois Haas considere que esta mística tiene raíces que llegan hasta el escepticismo de Pirrón de Elis (365-270 a. C.), quien adoptó la fórmula escéptica del juicio de los gimnosofistas, con quienes probablemente tuvo contacto en su viaje con Alejandro Magno a la India:

1. De "es" (posición $\chi 1)$

2. Y de "no es" (posición $\chi 2$ )

3. Así como la combinación "es" y "no es" (posición $\chi 3$ )

4. Y la de "ni es, ni no es" (posición $\chi 4$ )

Cuatro pasos que muestran que cualquier argumento puede ser refutado y, en consecuencia, no hay ninguna verdad definitiva, en un proceso que conduce al silencio, entendido como suspensión del juicio (epojé), y permite alcanzar la ataraxia. ${ }^{5}$ Una experiencia

${ }^{4}$ Teresa Rocha (1993) explica que, para Böhme, la relación entre el mundo invisible y el visible es un Mysterium magnum, porque, si bien el mundo invisible es la causa, explicación y posibilidad del mundo visible, este último es el que permite que el invisible pueda manifestarse: "por la ex-presión, por el ex-hálito de la palabra divina, como marco o instrumento de acción de lo invisible en la manera en que el alma obra por medio del cuerpo" (361).

${ }^{5}$ Sobre la relación entre la filosofía de Wittgenstein y el escepticismo pirrónico, véase Reinoso (2018). 
de incertidumbre que, como dice Haas (2009), será adoptada más tarde como una disposición necesaria para ser cristiano (32).

Es muy interesante descubrir lazos entre la poética del Tractatus y la de Sexto Empírico (160-210 D.C.), pues el filósofo pirrónico que practicó la disolución de los argumentos como cura contra el dogmatismo usó la metáfora de la escalera de la misma manera que aparece en el Tractatus: "Al igual que no es imposible que una persona que ha llegado a un lugar alto por una escalera, la tire una vez que ha subido por ella, no es improbable que el escéptico también, después de haber conseguido su tarea por una pequeña escalera -el argumento que muestra que no hay demostración- deba desechar tal argumento" (apud. Reinoso, 2014: 48-49).

Esto significaría que el Tractatus se liga a una tradición filosófica que se propone mantener la incertidumbre y el misterio, en lugar de superarlos, y que explica el interés en expresar lo trascendente en paradojas, como la que se produce en la convicción de que es posible un lenguaje acerca de lo imposible (Vega, 2011: 86). En el Tractatus, ese lenguaje da forma a una poética que parte del carácter trascendental de la lógica, cuyo lenguaje es un espejo ${ }^{6}$ donde el mundo toma una forma (Bild) cuando la proposición figura los hechos del mundo en el pensamiento y los muestra, como el espejo muestra una imagen.

${ }^{6}$ En el aforismo 5.511, se responde a la pregunta de cómo es posible que el lenguaje de la lógica refleje el mundo pero use tan extraños garabatos, explicando que se debe a que está unido "por una trama infinitamente fina al gran espejo"; y más adelante, el aforismo 6.13 se refiere también a este carácter especular de la lógica, al plantear que: "La lógica no es una doctrina, sino un reflejo del mundo. La lógica es trascendental". La paradoja especular del lenguaje remite a Böhme, para quien la sabiduría eterna de Dios es un ojo, "y, al mismo tiempo, el espejo en que Dios se refleja" (Seijas, 2010: 12). 
Desde esta perspectiva, resulta más claro el llamado de Wittgenstein a poetizar la filosofía ${ }^{7}$-lo que constituye su trabajo-, como una labor dedicada a la creación de una escritura adecuada para expresar el carácter trascendental que le atribuye a la lógica, ${ }^{8}$ que aquí se hermana con la ética, la estética y la religiosidad por su carácter místico, y en consecuencia, por una mirada sub specie aeternitatis, que es aquella que mira el mundo desde lo alto. Sin embargo, no se está hablando de campos de reflexión filosófica separados de la vida, ya que, si la obra de arte es el objeto visto $s u b$ specie aeternitatis, "la vida es el mundo visto sub specie aeternitatis. No otra es la conexión entre arte y ética" (Wittgenstein, 1986: 140).

Sabemos bien que no estamos ante una filosofía interesada en qué sea el mundo, sino de aceptarlo sea como sea. De ahí que afirme que "mundo y vida son lo mismo" (en el aforismo 5.621) y cobre sentido la búsqueda de una forma de vida adecuada para el propósito filosófico de cambiar la propia vida -para dejar de tener una vida falsa, diría Wittgenstein-, una exigencia que él considera

${ }^{7}$ Me refiero al famoso aforismo escrito entre 1933 y 1934: "Creo haber resumido mi posición con respecto a la filosofía, al decir: de hecho, sólo se debería poetizar la filosofía. Me parece que de ello se desprende en qué medida pertenece mi pensamiento al presente, al futuro o al pasado. Pues con ello me reconocí también como alguien que no puede hacer del todo lo que querría" (Wittgenstein, 1995: 65-66).

${ }^{8}$ La discusión que plantea Michael Wood (2010) sobre la traducción de la palabra dichten, en la frase en marras: "Philosophie dürfte man eigentlich nur dichten", que realmente sería intraducible, abre el abanico del sentido de "poético" en esta frase. Uno de sus posibles significados se referiría, no a la versificación, sino a la carga creativa e imaginativa de la escritura literaria en general, que es uno de sus sentidos en alemán. De ahí que otra posible traducción podría ser: "la filosofía debiera ser sólo escrita", en el sentido en que Barthes plantearía que, de no ser escritura, no sería nada. Pero, además, dado que no aparece el comparativo como, podría interpretarse que estrictamente dice que debe ser poesía (61). 
propia del cristianismo, como se revela en una anotación que hizo en 1946: "Opino que el cristianismo dice, entre otras cosas, que todas las buenas doctrinas no sirven para nada. Debe cambiarse la vida (o la dirección de la vida)" (Wittgenstein, 1995: 106).

La transformación de la propia vida responde a la búsqueda mística de un centro, ${ }^{9}$ es decir, al ajuste entre la vida y el mundo que en el Diario filosófico se plantea como condición para alcanzar la felicidad que otorga vivir en un eterno presente (Wittgenstein, 1986: 129). Es entonces cuando acepto que mi voluntad no puede cambiar los hechos del mundo, y que "sólo en la conciencia de la unicidad de mi vida surgen religión -ciencia-y arte” (134).

Quisiera proponer entonces que la filosofía de Wittgenstein, como forma de vida, es un acto de escritura que está fundado en una ética del asombro de que el mundo sea, que es análogo a ver el lenguaje como un milagro, como se plantea en la "Conferencia sobre ética" de 1929. Se trata de una experiencia y un sentimiento que se producen para Wittgenstein en una vida exílica de profunda espiritualidad, ya sea en las montañas noruegas o en el frente de guerra, pues esa es la manera de alcanzar la autoconciencia nece-

${ }^{9}$ Böhme se refiere al centro como el lugar de unión con lo divino: "la comprensibilidad está oculta en el centro, la fuerza divina que creó la comprensibilidad y que además la sostiene, lleva y rige" (Böhme, 1979: 321). Silesius (2005) hace varias referencias a este concepto místico de centro como imagen de la unidad de lo múltiple en el Uno: "II. 24. EL CENTro. Quien ha escogido para sí el centro por morada, lo que en la circunferencia hay ve de una sola mirada" (véase también: III, 28, 147; V, 212). Por otra parte, Mircea Eliade señala que la simbología del "centro" como el lugar donde se unen las tres zonas cósmicas: el cielo, el infierno y la tierra, está asimilado a una "montańa sagrada" desde la mitología mesopotámica. El ascenso del peregrino es la aproximación "al centro del mundo, y en la terraza superior realiza una ruptura de nivel, trascendiendo el espacio profano" (Eliade, 1979: 336). Una cuestión que calza muy bien con la metáfora del ascenso y la vida ascética en las montañas nórdicas, como se verá más adelante. 
saria para cumplir con su deber de tener una vida justa consigo mismo y así salvarse.

\section{La escritura de lo inefable}

Como la de todos los escritores místicos que, siendo poetas, son trabajadores del lenguaje, la obra de Wittgenstein es autobiográfica y confesional y se compone de un arsenal de escritos no académicos que dota a su filosofía de un fuerte carácter personal que Badiou considera característico de los que él denomina antifilósofos; quienes, como Pascal, Heidegger o Wittgenstein, tienen una inclinación al misticismo por su interés filosófico en el lenguaje. Para Badiou (2013), Wittgenstein es un héroe de nuestro tiempo (73) que estuvo "condenado" a la metáfora, en un acto de escritura que funda su concepción del trabajo filosófico como una actividad de creación y destrucción permanente de lo creado, cuyo fin es el de cambiar la vida para ser salvado. La confesión se convierte, entonces, en una especie de iluminación - "producción de luz", dice Badiou-, cuyo contenido lo aproxima a San Agustín por esa fusión de doctrina lingüística y vida personal. Pero también es semejante a la poesía de Mallarmé, porque, igual que en "Un golpe de dados", hay una "tensión metafórica combinada con un rigor matematizante, la ironía latente de las figuras, la absoluta autosuficiencia que remite, no obstante, a un 'más allá del Libro" (86).

Esta cualidad estética del lenguaje místico se relaciona con un carácter apofático que se crea a través de la transgresión de la lógica gramatical, como señala Hass (2009):

El modus loquendi místico gusta de utilizar modos de hablar antilógicos, en ocasiones de manera incluso abusiva. Con razón, Hugo Ball y Emmy Ball-Hennings, máximos representantes de los dadaístas de Zúrich y "ditirámbicos de la ruina” de los valores, 
declamaban textos de místicos medievales (como por ejemplo de Mechthild von Magdeburg), entre otros, con el objetivo de que sus acciones perturbaran los sentidos (19).

Esa expresión apofática es la que dominó Silesius en su poesía religiosa, la cual, como considera Hadot (2007), debió familiarizar a Wittgenstein “con las paradojas místicas más audaces” (53).

En los Diarios secretos, en una anotación de 1916, Wittgenstein se refiere al problema de expresión que enfrenta para hablar de la conexión entre su trabajo matemático y el de lo divino y lo humano, a lo que responde: “¡Pero esa conexión llegará a establecerse! ¡Lo que no se deja decir, no se deja decir!” (Wittgenstein, 1991: 153). Y antes, en una temprana nota de 1914, dice: "Detrás de nuestros pensamientos, verdaderos o falsos, yace una y otra vez una raíz oculta, que solo después sacamos a la luz y expresamos como un pensamiento" (63). Unos meses más tarde, confesará que su dificultad "es una enorme dificultad de expresión" (73). Es aquí donde hace presencia la poesía religiosa de Silesius como la posible inspiración para la aforística del Tractatus.

Johannes Scheffler, quien tomó el nombre de Angelus Silesius cuando se convirtió al catolicismo, decepcionado de la ortodoxia luterana, llevó a grandes alturas el ejercicio que llevaba a cabo el grupo de Abraham von Franckenberg en la ciudad de Öls, quien había conocido muy bien a Jacob Böhme, y cuyos discípulos, entre los que estaba Silesius, escribían aforismos religiosos (Silesius, 2005: 13).

La empresa de construir un lenguaje que le permita entablar un diálogo con Dios, conduce a Silesius a la situación paradójica, que señala Josef Sudbrack, de ser prisionero de su lenguaje a la vez que transgresor del lenguaje, de modo tal que obliga al lenguaje a ser "más que lenguaje", por medio de paradojas y tautologías (apud. Silesius, 2005: 11). Una condición en la que, para Duch, "el len- 
guaje remite a la individualidad del hablante y, de esta manera, remite a algo situado más allá de él mismo y de sus informaciones, hacia lo que la religión y la filosofía acostumbran a designar con el nombre de trascendencia" (11). Una trascendencia que, si se logra mediante la transgresión del lenguaje, es porque Dios es un reflejo del mundo, pero no un ente del mundo, que es la que condición paradójica que debe perseguir el lenguaje religioso, según Böhme, dado que "el gran misterio de la palabra hablada es que hay detrás de ella una Palabra hablante ("das ewige sprechende Wort") que es, a su vez, "unaussprechlich" (habla pero no puede ser hablada)" (Rocha, 1993: 361).

La escritura aforística del Tractatus sigue la misma regla de los místicos que se reunían en Öls, de usar un lenguaje sintético y breve, además de paradójico y sentencioso, por ser esta la simbolización más apropiada para la condición de lo divino en el lenguaje.

Sin embargo, esta escritura es inseparable de una vida ascética y exílica que se plantea como un ideal de santidad, la cual Wittgenstein comparte también con Silesius, quien, siendo médico por sus estudios universitarios, gozaba de una fortuna a la que renunció para retirarse a vivir al Convento de San Matías de Breslau, en Italia, donde murió. Una decisión que también tomó Wittgenstein, no sólo porque renunció a su fortuna, que era la más cuantiosa de Europa, sino porque también vivió por un tiempo en un monasterio de Viena, después de la guerra, haciendo las tareas de jardinero, e intentó ser monje ahí para llevar la vida de esos cristianos sin iglesia que lo antecedieron, como Angelus Silesius.

La forma de vida filosófica es una experiencia mística (ética y estética), a la manera en que Silesius concibe la "muerte eterna", en su epigrama 29 del libro primero: "La muerte de la que no florece una vida nueva: de esa huye mi alma de entre todas las muertes". Y más adelante, en el epígrafe 192 del libro siguiente, lo plantea como un llamado: "Ah, hermano, vuélvete pues: ¿por qué 
sigues siendo humo y apariencia? Tenemos que volvernos esencialmente un ser nuevo". Para Wittgenstein, "revolucionario será aquel que pueda revolucionarse a sí mismo" (Wittgenstein, 1995: 96), y cambiar su vida es la condición para pensar por sí mismo y conseguir el ideal filosófico de encontrar su centro, que sin duda encontró en Skjolden.

\section{Un lugar sagrado}

He estado tres veces en Skjolden, ${ }^{10}$ la última en el verano de 2019, cuando concluyó la reinstalación de la cabaña de Wittgenstein en su sitio original en el lago Eiden, ya que el heredero la trasladó al pueblo después de que murió el filósofo. La fundación Wittgenstein de Skjolden compró otra casa en 2018 y empezó a hacer el traslado de todas las piezas de la antigua construcción, así como de los muebles originales que habían sido celosamente conservados, junto con algunos objetos personales, como sus artículos para afeitarse.

Pasé una mañana luminosa en la cabaña con mi amiga Siri Almetun, después de que conseguimos las llaves y emprendimos el difícil ascenso hasta arriba del acantilado que se refleja en el lago. Es una experiencia conmovedora poder estar ahí, al lado de la misma mesa donde Wittgenstein escribió en completo aislamiento, y sobre todo, poder admirar desde el balcón del segundo piso, donde lo solían ver los vecinos muchas tardes, el paisaje del lago con el pueblo al fondo, enmarcado por las montańas que custodian el final del trayecto del fiordo, al que Wittgenstein le atribuyó la majestuosidad de una "silenciosa seriedad" que sin duda refiere a

${ }^{10}$ Sobre mi primer viaje a Skjolden en 2017, véase mi artículo: "Una peregrinación filosófica a un espacio para pensar. La cabaña de Wittgenstein en Skjolden, Noruega" (en prensa). 
ese "estado de ánimo poético" al que Schiller aludió en una carta a Goethe -como recuerda Wittgenstein en una nota de 1948-, y con el cual se identifica: "Creo que sé a lo que se refiere, creo conocerlo. Es aquel estado de ánimo en el que se es receptivo a la naturaleza, y en el que los pensamientos parecen tan vivos como la naturaleza" (Wittgenstein, 1995: 124).

El lector de Wittgenstein que llega hasta este espacio sagrado también encuentra su centro ahí. La unión del peregrino y el filósofo en esa escritura mística se transforma en la cabaña en una hierofanía de la inclinación humana a decirse a sí mismo, en las letras que la mano escribe, lo indecible.

\section{Bibliografía}

Badiou, Alain, 2013, La antifilosofía de Wittgenstein, Ma. del C. Rodríguez (trad.), Capital Intelectual, De Autor 13, Buenos Aires.

Böhme, Jacob, 1979, Aurora, A. Andreu (trad., pról. y notas), Alfaguara, Madrid.

J. Bremer, 2020. "An Artistic rather than a Scientific Achievement. Frege and the Poetically of Wittgenstein's Tractatus", Philosophia, Jesuit University Ignatianum in Krakow. Disponible en: https://doi.org/10.1007/s11406-020-00216-3 (Consultado: 30/X/2020).

Eliade, Mircea, 1979, Tratado de historia de las religiones, T. Segovia (trad.), Era, México.

Haas, Alois M., 2009, Viento de lo absoluto. ¿Existe una sabiduría mistica de la posmodernidad?, J. Seca (trad.), Siruela, El Árbol del Paraíso 65, Madrid.

Hadot, Pierre, 2007, Wittgenstein y los limites del lenguaje, M. Arranz (trad.), Pre-textos, Valencia. 
Hernández Martínez, Laura A. "Una peregrinación filosófica a un espacio para pensar. La cabaña de Wittgenstein en Skjolden, Noruega", en Arte, ciencia y palabra. Escritos sobre viajes y viajeros, Carolina Depetris (ed.), Centro Peninsular en Humanidades y Ciencias Sociales / Universidad Nacional Autónoma de México [en prensa].

Monk, Ray, 1994, Ludwig Wittgenstein, D. Alou (trad.), Anagrama, Barcelona.

Reinoso, Guadalupe, 2014, "La escritura escéptica como clave de lectura: los prólogos de Wittgenstein”, Tópicos, núm. 27, Santa Fe, Argentina, julio, pp.46-61.

,2018, "Las preguntas metafísicas y otras enfermedades filosóficas: Wittgenstein y el pirronismo”, Skepsis, vol. IX, núm.17, pp. 99-113.

Rocha, Teresa, 1993, "Un apunte sobre la historia de la teoría del lenguaje: Böhme, Saint-Martin y Kleuker", Anuario de estudios filológicos, vol. 16, Univ. de Extremadura, pp. 351-366.

Seijas, Carlos, 2010, "La libertad como fundamento del ser", Eleutheria, núm. 2, Universidad Francisco Marroquín, Guatemala. Disponible en: http://www.ufm.edu (Consultado: 09/ IX/2020).

Silesius, Angelus, 2005, El peregrino querúbico, L. Duch (introd., trad. y ed.), Siruela, El Ârbol del Paraíso 41, Madrid.

Vega, Amador, 2011, Tres poetas del exceso. La hermenéutica imposible en Eckhart, Silesius y Celan, Fragmenta Editorial, Barcelona.

Weeks, Andrew, 1993, German Mysticism from Hildegard of Bingen to Ludwig Wittgenstein. A Literary and Intellectual History, State University of New York, Nueva York.

Wittgenstein, Ludwig, 1971, Prototractatus, D. F. Pears \& B. F. McGuinness (trad.) Routledge \& Kegan Paul, Londres. 
, 1987, Tractatus logico-philosophicus, E. Tierno Galván (trad.), Alianza Editorial Mexicana, Alianza Universidad 50, Madrid.

, 1986, Diario filosófico (1914-1916), J. Muñoz e I. Reguera (trad.), Editorial Planeta-De Agostini, México.

, 1991, Diarios secretos, A. Sánchez (trad.), Alianza Editorial, Alianza Universidad 670, Madrid.

1989, Conferencia sobre ética. Con dos comentarios sobre la teoría del valor, F. Birulés (trad.), M. Cruz (intro.), Paidós / Instituto de Ciencias de la Educación- Universidad Autónoma de Barcelona, Pensamiento Contemporáneo 1, Barcelona.

1995, Aforismos. Cultura y Valor, E. C. Frost (trad.), Espasa Calpe, Colección Austral 381, México.

, 1979, Cartas a Russell, Keynes y Moore, N. Míguez (trad.), Taurus Ediciones, Ensayistas 165, Madrid.

Wood, Michael, 2010, "Como una enfermedad. La escritura y la filosofía según Wittgenstein”, Valenciana. Estudios de Filosofía y Letras, núm. 5, Universidad de Guanajuato, enero-julio, pp. 57-66. 